\title{
A Case Study in Globalized Agribusiness Ethics: An Herbicide in the Spotlight
}

\author{
Dr. Jenita Thinakaran, MSc (Ag), PhD. \\ Professor and Department Head, School of Agriculture \\ Karunya Institute of Technology and Science \\ E-mail: jenita@karunya.edu
}

Dr. C.Chinnusamy, MSc(Ag), PhD., PDF, FISA, FISWS, FCWSS

Professor and Department Head, School of Agriculture

Karunya Institute of Technology and Science

E-mail: chinnusamy@karunya.edu

\begin{abstract}
Dr. Mark Wm Cawman, DBA, MBA, BSM
Assistant Professor of Management and Director of International Business

School of Business and Management, Azusa Pacific University

E-mail: mcawman@apu.edu
\end{abstract}

\section{Affiliation and Contributions:}

Dr. Thinakaran and Dr. Chinnusamy are professors of Agronomy (Agriculture, Horticulture, and Entomology) at Karunya Institute of Technology and Science in India. Dr. Cawman is a professor of Management (International Business, Strategic Management, and Organizational Performance) at Azusa Pacific University in California, USA. These authors have teamed up to present this case study as an ethical study in globalized agribusiness.

Received: January 10, 2022 Accepted: January 26, 2022 Published: January 30, 2022 doi:10.5296/csbm.v9i1.19457ＵRL: https://doi.org/10.5296/csbm.v9i1.19457 


\section{Abstract}

This case study considers the growth, industrialization, and globalization of agribusiness in feeding the world, and the efficiencies sought through various innovations, especially pesticides. A particular herbicide (a subset of a pesticide) has significant ethical dilemmas, misinformation, disinformation, and possibly big business bias - all surrounding the debate on the continuance of use and potential collateral safety issues. This case considers Corporate Social Responsibility and ethics as well as the tensions between efficiency and collateral issues in business decisions. There are scientific reports that can support various conclusions and ongoing litigations use these in support of rulings that also have gone both ways. This continues to be a dynamic issue as science and court rulings occur, but this case study is of interest and significance to the business, international business, agribusiness, and agronomy fields of study as typical to decisions various stakeholders face.

Keywords: agriculture, ethics, herbicides, glyphosates, Roundup, globalization, agribusiness

\section{Introduction}

This case study is intended to present an overview of the literature and key constructs for deliberation, debate, and learning. This is not a research report with new findings, nor is it a persuasive paper to influence a particular outcome or persuasion. This case study is a useful exercise in ethical considerations in agribusiness and globalized industry and considers a case study product with both positive utility and possible collateral issues of harm or concern.

Agriculture or farming has seen significant shifts toward large enterprises and away from the traditional, small, and family-owned establishments (Dukeshire, 2013). That said, the historical farm image has persisted, and agriculture is not always thought of as an industry or business, even though it is the largest industry in the world. Because it operates on the land -- in fields, pastures, etc., it is also usually thought of as a very domestic versus globalized-oriented business. The reality is that agriculture is big business, is an industry (Friedmann, 1991), and is increasingly globalized (Robinson, 2018). All of the factors that have accelerated globalization (e.g., lowered barriers to trade, technology, infrastructure, transportation, specialization, hybridization of cultures, etc.) have also accelerated agri-food systems and agribusiness. The industrialization and globalization of agriculture have both helped and hurt various populations. Small farms have been swallowed up or put out of business and regulations and food safety have been friendly to big business (Dukeshire, 2013). Some argue that the general supply, yields (Zhao et al., 2017), and cost of food have become more widely available and therefore are feeding greater populations around the world (Global Agriculture, n.d.) through this big-business shift. Critics suggest that this is not entirely true, that small farms can extract more yield per acre, and that the benefits of large and globalized agribusiness are not enough to offset the harm (Norberg-Hodge et al., 2002). Overall, there are many debates on the benefits or harm of big business farming, but the reality of their presence is real and significant (Robinson \& Carson, 2015). Like many other industries, agri-businesses try to improve their profits through market expansions (topline/revenue) and cost reductions (bottom-line/cost of goods sold [COGS]). 


\section{Macrothink}

\subsection{Market Expansions}

The market expansions have moved beyond local distribution and agribusiness has become globalized like many other industries. Food products from these mega-farms are shipped around the world by air and sea. We continue to see a world fundamentally shifting away from fully autonomous or self-contained economies and distinctive indigenous cultures and customs (United Nations Educational, Scientific, and Cultural Organization [UNESCO], 2017) that were historically isolated by distance, time, language, and policies - an effect we know as globalization. Globalization has caused hybridization of tastes and trends and has therefore increased demand for certain products - allowing mega-farms to increase production outputs, and market and ship these products to new and expanded global markets.

\subsection{Cost Reductions}

The factors of production (labor, materials, logistics, capital, etc.) are always considered by businesses for efficiency and cost-cutting. If businesses (regardless of industry) can save labor, material, shipping/handling, and/or utilize less capital - improvements are seen in the COGS (Cost of Goods Sold). Reduction in these direct costs increases profits, and larger enterprises especially can see small changes accumulate to large savings. Agricultural losses are costly and using the country of India as an example, 34\% of losses to pests are to weeds and/or unwanted vegetational encroachments as shown in figure 1. Some weeds are particularly more egregious in their impact on crop yields, based on either their relative leaf size/area, their particular intrusiveness, and/or their nutrient demands (Lotz et al., 1996).

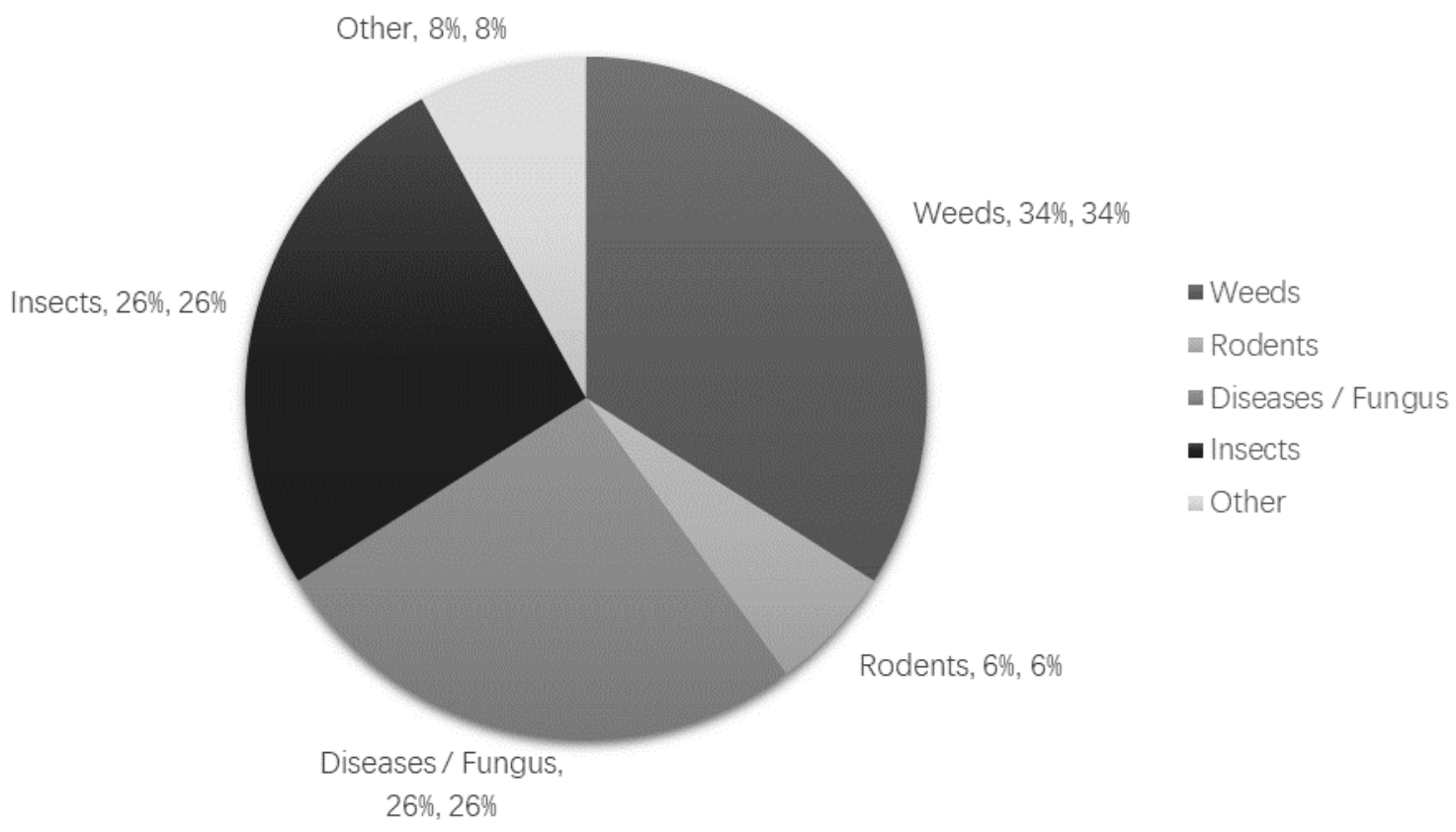

Figure 1. Losses Caused by Different Pests in India

Note. Source Data: Industry Reports, Analysis by TATA strategic management group (2014) in (Federation of Indian Chambers of Commerce \& Industry [FICCI], 2015, Figure 1) 


\section{Ml Macrothink}

Agriculture and farming were historically a labor and land-intensive industry for millenniums, and agriculture is the oldest industry in the world (Sigrimis et al., 2001). As industry was mechanized through the industrial revolution, technologies also supported the agriculture industry (e.g., tractors, milking machines, improved irrigation, etc.). The industrial revolution of farming is not complete either, as the fourth industrial revolution (e.g., artificial intelligence and programmed mechanization) is and will continue to revolutionize the industry of agriculture (Sung, 2018). In efforts to further reduce costs, chemical engineering advances were deployed to assist in reducing waste from pests (insects, birds, weeds, etc.). This facilitated significant labor reductions in tillage and tending of fields and crops (Uri, 2000). This also improved yields and utilization of topographies and geographies that were previously difficult to farm (Gronau, 2017). The savings in labor helped navigate other challenges as some regions of the world experienced relevant labor shortages due to the migration of workers from rural to urban, and from agriculture to manufacturing, technology, or service industries (Katz \& Stark, 1986; Stark, 1984). The drive for cost savings pushed for the reductions in tillage and insect damages. The primary objective of using herbicides is to improve agricultural productivity by killing unwanted herbs and weeds that either choke out the desired crops or inhibit production yields. Demand has continued to increase for agricultural productivity to meet the global food demands, significantly driving the growth of the herbicides market. The global food demand is accelerated by the surge in population and the rise in disposable income of developing regions such as the Asia-Pacific, and these are causal to concomitant increases in the demand for herbicides. To realize the production efficiencies, significant demand for specially designed pesticides and herbicides has continued to increase [see definition note].

DEFINITION NOTE: An Herbicide is a substance used to control specific vegetation, but an herbicide is a type of pesticide, as it eliminates unwanted (e.g., pest) vegetation that is harmful to the desired vegetation (e.g., crops or desirable pasture vegetation).

\section{4) pes·ti-cide}

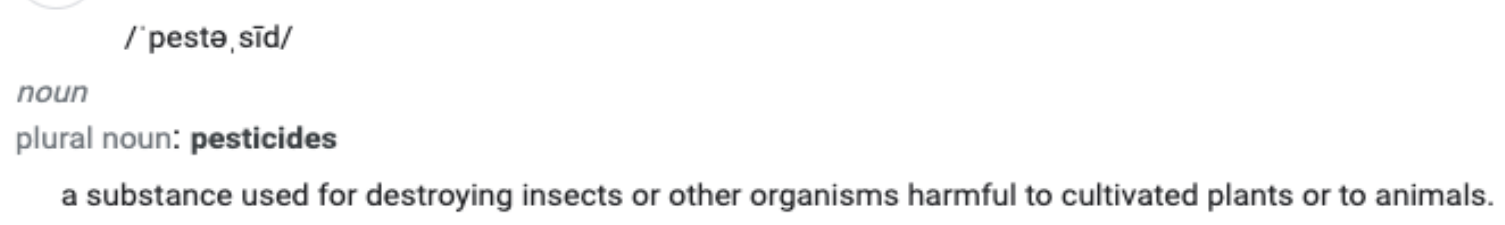

Image retrieved from (Google Dictionary, n.d.)

\section{The Product, Industry, and Business Environment}

Herbicides are a specific category of pesticides used to control unwanted plants during cultivation. Also known as weed killers, herbicides are of two types, selective and non-selective herbicides. Selective herbicides control specific weed species, leaving the desired crop unharmed, whereas non-selective herbicides can be used to clear industrial and 
construction sites, railways, and railway ridges as they kill all plant material with which they come into contact.

The global herbicides market is segmented as shown in table 1 and distributed/utilized as shown in figure 2 .

Table 1. Global Herbicide Market Segmentation

\begin{tabular}{|l|l|l|}
\hline Mode of Action & Crop Type & Region \\
\hline Selective (crops) & Corn & North America \\
\hline Non-Selective (sterilization) & Cotton & Europe \\
\hline & Soybean & Asia-Pacific \\
\hline & Wheat & LAMEA (Latin America, Middle East, and Africa) \\
\hline & Others & \\
\hline
\end{tabular}

Note. Source (Yenduri \& Sumant, 2019)

Further segmentation of herbicides is synthetic versus organic/biological (BIO). The BIO is the fastest growing and projected fastest-growing segment (Yenduri \& Sumant, 2019, Figure Global Herbicides Market by Type). Herbicides are the most largely consumed among all pesticides (from the group of insecticides, herbicides, and fungicides), but the proportion varies in different countries. North America is the leading consumer of herbicides due to the trend of early adoption of technology in the developed countries of the region. In this region, the application of herbicide is not limited to agricultural use in fields and crops, but it is also used for weed management in lawns and forests, sterilization of construction projects, aquatic vegetation control, as well as many other uses (United States Environmental Protection Agency [EPA], n.d.). There is considerable and continuing market growth, and North America and Asia-Pacific are expected to be the fastest-growing markets at a Compound Annual Growth Rate (CAGR) of 3.9\% and 6.5\%, respectively. This may change though, as research has accelerated the use of herbicides in wildlands and other range and natural areas to assure that plant breeds remain exclusive to native or indigenous species (Rew et al., 2007; Skurski et al., 2013). This could position other areas such as South America as the leading consumer. The global herbicide market size is expected to reach overall market revenue of $\$ 7,998.9$ million by 2025 , by growing at a CAGR of $4.8 \%$ (Yenduri \& Sumant, 2019).

There is necessary agricultural engineering (genetically modified corn, cotton, soybeans, etc.) to counter plant adaptation and resistances to herbicides (Wechsler et al., 2019) that affects the selective mode-of-action herbicides. Research and data analytics can help manage this, and Clearfield Canola Production System "is a globally-recognized non-genetically modified herbicide tolerance (HT) system” (Yenduri \& Sumant, 2019). 


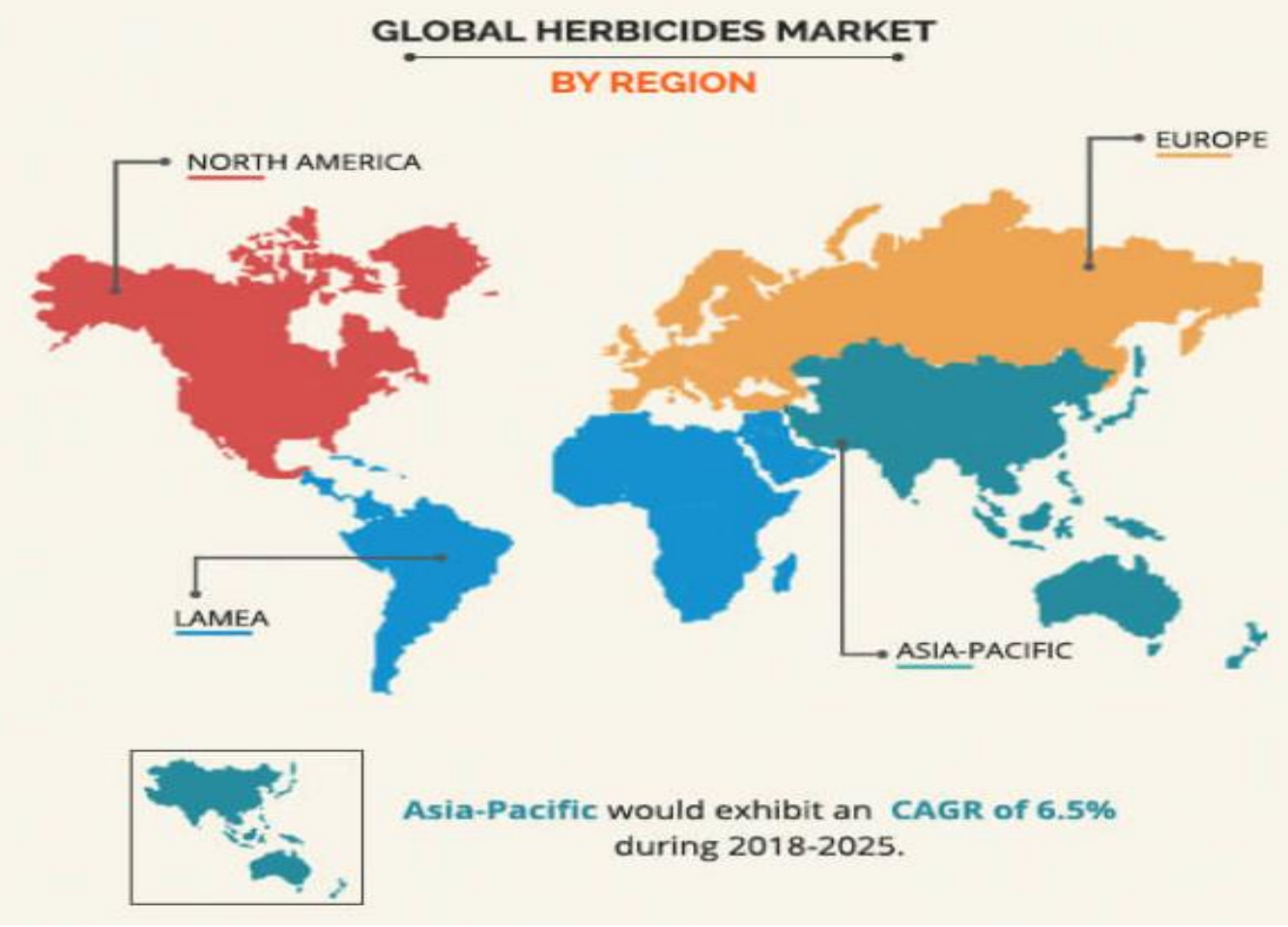

Figure 2. Global Herbicides Market by Region

Note. Source (Yenduri \& Sumant, 2019, Figure Global Herbicides Market Share, by Region).

Like many large globalized industries, the herbicide companies are continually evolving to stay competitive including acquisitions, mergers, and innovations. Some of the large companies in these markets are BASF, Bayer AG, DowDupont, Syngenta AG, FMC Corporation, Adama Agricultural Solutions Ltd, and Nufarm Ltd. (Yenduri \& Sumant, 2019).

The most commonly used synthetic herbicides include glyphosate 2, 4-D, atrazine, glufosinate-ammonium, paraquat, pendimethalin, dicamba, fluroxypyr, and metolachlor. However, the growth of the market is mostly driven by the application of glyphosate. Crops such as soybean, maize, cotton, and wheat are major crops that dominate the sales of herbicides. This case study focuses particularly on one of the synthetic herbicide categories -glyphosates. Many companies have sold various glyphosates, but one, in particular, is widely recognized -- Roundup ${ }^{\circledR}$. Roundup was a product of Monsanto but was acquired by Bayer in 2018 (Roundup, n.d.). With Roundup, the pounds applied increased while the cost to do so decreased, and rapid adoption across crops resulted. In just 2014 "farmers sprayed enough glyphosate to apply $\sim 1.0 \mathrm{~kg} / \mathrm{ha}(0.8$ pound/acre $)$ on every hectare of U.S.-cultivated cropland and nearly $0.53 \mathrm{~kg} / \mathrm{ha}(0.47$ pounds/acre $)$ on all cropland worldwide" (Benbrook, 2016). Glyphosate is the highest consumed herbicide in the prevailing market condition and is also expected to retain its lead. The global market of glyphosate is expected to grow with a significant CAGR. Being an effective and low-cost solution, glyphosate is largely used in various applications in all geographies. As evident in figure 3 and figure 4, glyphosate use accelerated (example - United States) with the 
introduction of Roundup.

Glyphosate Use in the United States: 1974 to 2014

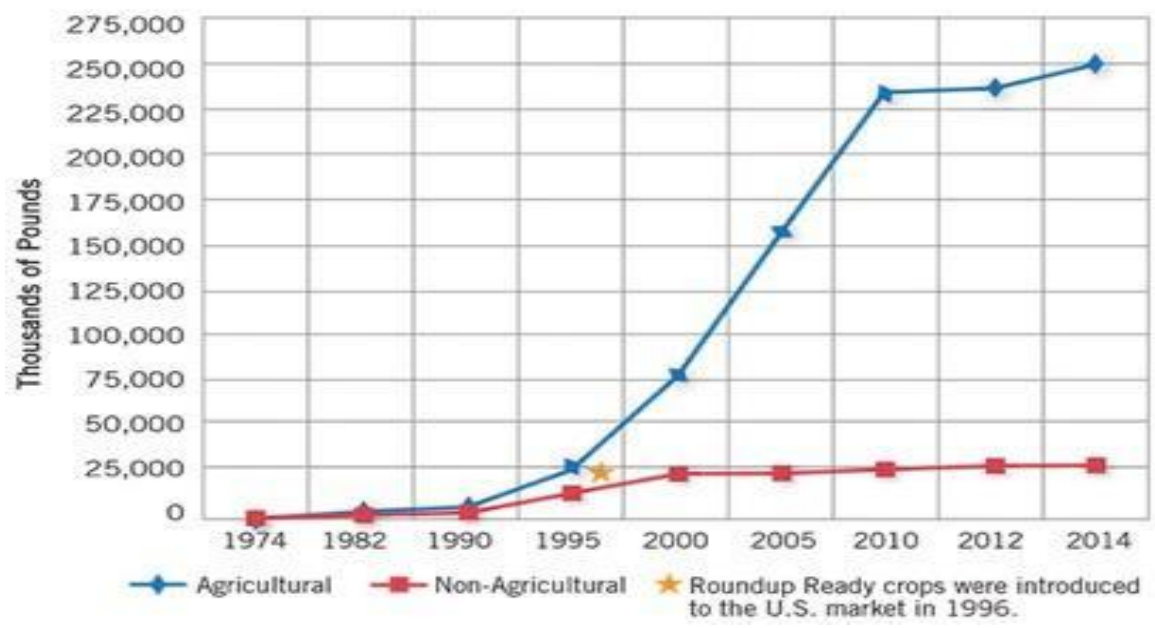

Figure 3. Herbicide Statistics - Trends in Glyphosate Use

Note. Image Retrieved 31 October 2021 from (Clark, n.d.)

The growth in the United States is not unique, as other countries have seen exponential growth as well. India is another example, and about 0.866 million $\mathrm{kg}$ of glyphosate was sold in 2014-15, according to the Directorate of Plant Protection, Quarantine and Storage (Directorate of Plant Protection, Quarantine, and Storage [PPQS], 2021).

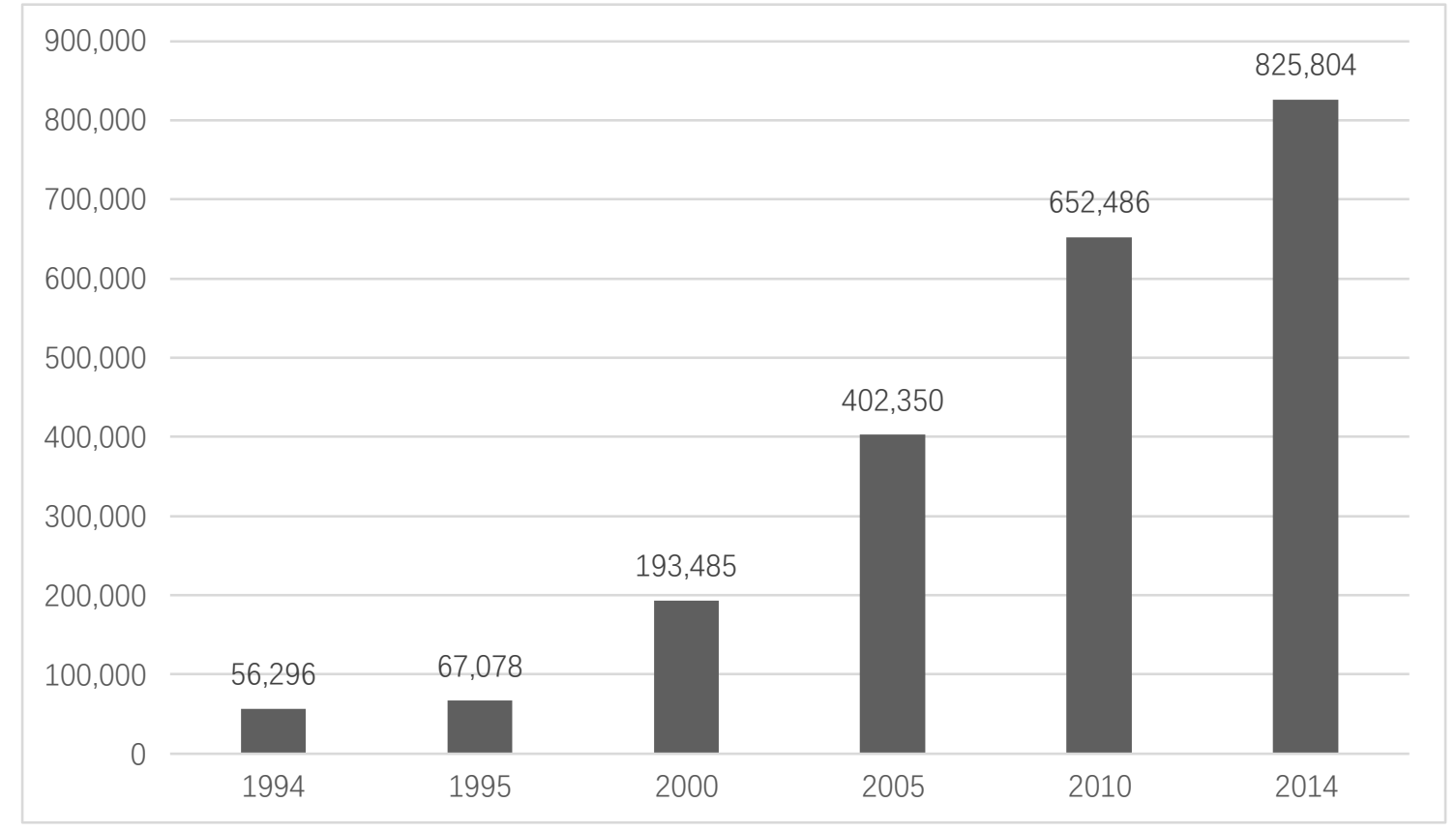

Figure 4. Glyphosate 20 year use worldwide from 1994 to 2014 (1,000 kilograms) Note. Source / Data Retrieved From (Statista, 2016) 


\section{The Science and History}

Glyphosate was first synthesized in Switzerland in 1950 by a Swiss chemist, Dr. Henry Martin, working for a pharmaceutical company; the molecule was on-sold through a series of companies and tested for possible uses until herbicidal action was identified in 1970 by Dr. John Franz, a scientist working with Monsanto Company of St Louis, Missouri, USA (Benbrook 2016). Monsanto developed this into the herbicide Roundup ${ }^{\circledR}$ in 1974, which was subsequently acquired by Bayer in 2018 (Bayer, n.d.). Global production of glyphosate-based herbicide is estimated to be around 1,065,000 tons; 35\% by Monsanto (Bayer), and 65\% made in China (PR Newswire, 2018). In addition to Monsanto/Bayer, there are several producers including Nufarm, Syngenta, Dow AgroSciences, and DuPont. In 2011 China's capacity alone was 835,900 metric tonnes, more than enough to meet global demand, and so there is huge over-supply capacity. With this capacity, there is significant pressure to decrease prices and to disperse Roundup ${ }^{\circledR}$ Ready genetically modified crops (Székács \& Darvas, 2011).

Glyphosate is the active ingredient present in many herbicides including the popular Roundup and is used in the control of weeds and grasses (US Environmental Protection Agency [US EPA], n.d.). Glyphosate has been registered in the United States as a broad-spectrum herbicide since 1974, which means it cannot be used to kill specific weeds or plants. It kills all broadleaved plants in the area (Henderson et al., 2010). It acts by preventing the synthesis of three amino acids namely, phenylalanine, tyrosine, and tryptophan by inhibiting the plant enzyme 5-enolpyruvyl-3-shikimate phosphate synthase (Baer \& Marcel, 2014). As an example of how this works, it would be like when human cells that do not secrete insulin in required amounts, result in type 2 diabetes or hyperglycemia. Some important facts about glyphosate as summarized by Brown et al. (2019).

Glyphosate is the world's most popular and abundantly used non-selective herbicide with about 300 million pounds used globally in one year. Glyphosate kills plants within 20 days by preventing the shikimic acid pathway present in plants responsible for the production of phenylalanine, tyrosine, and tryptophan. Runoff water barely contains glyphosate as it quickly binds to soil particles and any leftover glyphosate gets degraded to glycine, phosphate, and carbon dioxide. Exposure through inhalation is negligible as it is a non-volatile part of the ingested product that is absorbed and excreted and dermal exposure could result in about $2 \%$ absorption through the skin. Although the International Agency for Research on Cancer (IARC) has categorized glyphosate as 'probably carcinogenic to humans' no other scientific data has been proven to confirm the same. The US Environmental Protection Agency (EPA) has ruled out any association of glyphosate with human cancer if used in accordance with label directions and considers it as a false claim that does not meet the labeling requirements of the Federal Insecticide, Fungicide and Rodenticide Act (FIFRA).

Glyphosate is a modified glycine-molecule (the smallest of our essential amino acids) which has a phosphoric acid (or to be exact, phosphonomethyl) group attached at the end (GLYcine

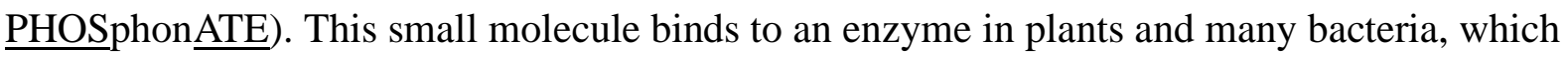


they need to synthesize a class of amino acids (aromatic ones). In the absence of these amino acids, plants will die in a few days. Humans and animals do not have this enzyme and depend on an external source/diet to provide us with these aromatic amino acids (Tryptophan and Phenylalanine - and Tyrosine), which means that the inhibitory effect of glyphosate has no direct target in our cells. It has a broad spectrum of activity and is highly effective and inexpensive. It is not volatile, has no odor, and has little to no residual soil activity. In addition to the listed attributes, glyphosate has a very favorable safety profile for mammals and aquatic life. Glyphosate is a "dirt lover" and will bind tightly to most soil and sediments in the environment. Glyphosate is degraded into carbon dioxide and phosphate by microorganisms and, thus, does not bioaccumulate. Farmers quickly adopted glyphosate for agricultural weed control after Monsanto introduced glyphosate-resistant Roundup Ready® modified seeds for crops, enabling farmers to kill weeds without killing their crops. This essentially makes the non-selective herbicide work in a selective manner, expanding its utility.

\section{Roundup® - A Brand (and Branded) Name}

Roundup is a very popular herbicide or weed killer. Produced by biotech giant Monsanto, it was first introduced by them in 1974. It was acquired by Bayer in 2018 and continues to be marketed under the same brand name. This weed killer is most commonly used in agriculture, but it is also used by the forestry industry, cities, and private homeowners. The key ingredient in Roundup is glyphosate, a compound with a molecular structure similar to the amino acid glycine. Glyphosate is also used in many other herbicides. This makes Roundup (like all glyphosate-based herbicides) a non-selective herbicide, meaning that it will kill most plants it comes in contact with. It is used for crops because the seeds have been genetically modified to be glyphosate-resistant. Glyphosate kills plants by inhibiting a metabolic pathway called the shikimate pathway. This pathway is crucial for plants and some microorganisms but does not exist in humans. However, the human digestive system does contain microorganisms that make use of this pathway. Roundup is a highly debated topic these days and thus is not just a brand name, but a "branded name" - with a great deal of notoriety. Some studies (Cressey, 2015; Guyton et al., 2015; IARC, 2017; Myers et al., 2016) claim that the active ingredient, glyphosate, may be increasing the risk of many diseases. On the other hand, Roundup has long been considered one of the safest herbicides available on the market as reported by (Bayer, n.d.-a; Environmental Protection Agency [EPA], 2016). While the EPA confirms there is no evidence of glyphosate-induced mutations, IARC reports glyphosate as "probably carcinogenic" as reported by Benbrook (2019) and (Portier et al., 2016) raising concern over the differing science and conclusions reported by the EPA and IARC. It is important to also note that Roundup contains more than just glyphosate. It contains a lot of other ingredients, which help make it a potent weed killer. Some of these ingredients are kept as trade secrets and protected under intellectual property parameters by the manufacturer. When an ingredient is under certain percentages by volume and/or not considered the "active ingredient," they are not required to be disclosed and are cataloged as "inert ingredients." At least one study (Mesnage et al., 2014) suggests that Roundup is significantly more toxic to human cells than just the active ingredient 
glyphosate. The result is that studies showing the safety of isolated glyphosate may not apply to the entire Roundup mixture, which is a blend of many chemicals (Mesnage et al., 2014). Conversely, as some of the legal and safety issues of Roundup are considered and/or litigated, these might not be warranted for extensions to the entirety of glyphosate and/or synthetic herbicides. Additionally, some of the "Roundup Ready" genetically modified crops, meant to be resistant to Roundup to essentially make the non-selective herbicide work in a selective manner, may also be separate safety or health considerations that may not be appropriate to extend to either Roundup or glyphosates (Cuhra, 2015).

\section{The Collateral Issues, Risks, and Litigious Environment}

Hazards have been associated with synthetic herbicides leading to risks, pull-backs, and stringent regulations on the use of herbicides. These all majorly hamper the growth of the global herbicides market. Glyphosate (and/or the brand name - Roundup) has become a word that for some people incites fear and misunderstanding. In recent years, there have been social media posts and articles (Bus, 2015) claiming that glyphosate has been found in human breast milk and cereal. While both of these claims have been disproven (Washington State University [WSU], 2015), this continues to cause concern for many. In the fall of 2018, a California jury awarded a groundskeeper \$289 million in a civil suit against Monsanto's Roundup (now Bayer) with the active ingredient glyphosate (Bellon, 2018). A year later, in March 2019, A California man was awarded $\$ 80$ million in a trial verdict over his claim that Roundup caused his non-Hodgkin's lymphoma (Sokolove Law, n.d.), and in May 2019 another California jury awarded a couple just more than $\$ 2$ billion in a similar case (Gonzales, 2019). These cases are currently being appealed, but Bayer has lost a third appeals case over glyphosate (Reuters, 2021). The litigation environment is dynamic, so these are a few cases for example, but this is not the exhaustive or conclusive outcomes; in fact, the rulings of these cases have initiated further civil lawsuits against Monsanto and now extending to Bayer following the acquisition. When watching television, viewers are barraged with commercials for class-action lawsuits against Roundup weed killer. This may unnecessarily strike fear into people not familiar with this product.

While glyphosate and formulations such as Roundup have been approved by regulatory bodies worldwide, concerns about their effects on humans and the environment persist and have grown as the global usage of glyphosate increases. Several regulatory and scholarly reviews have evaluated the relative toxicity of glyphosate as an herbicide (Hoss et al., 2003). The German Federal Institute for Risk Assessment toxicology review in 2013 found that the positive correlations reported concerning exposure to glyphosate formulations and risk of various cancers, including non-Hodgkin lymphoma was inconclusive as "the available data is contradictory and far from being convincing" (Tarazona et al., 2017; Travlos et al., 2017). In contrast, a meta-analysis published in 2014 identified an increased risk of Non-Hodgkin Lymphoma (NHL) in workers exposed to glyphosate formulations (Zhang et al., 2019).

Much media and public attention on glyphosate occurred after World Health Organization (WHO) subgroup, International Agency for Research on Cancer (IARC), declared that according to their classification, glyphosate falls under substances 2a - "probably 
carcinogenic" (e.g., cancer-causing) (International Agency for Research on Cancer | World Health Organization (WHO) [IARC], 2017). What the media attention often failed to report is that IARC does not look at risk - how significant is the risk for said carcinogenic effects? What levels or thresholds are safe and subsequent escalating levels and risks? Specifically, the scale used for this classification is as follows (International Agency for Research on Cancer [IARC], 2021):

1) definitely carcinogenic

2a) and 2b), probably and possibly carcinogenic

3) not classifiable, and

4) probably not carcinogenic.

For comparison purposes, red meat is identified as a carcinogen - also without exposure levels or limits, and also without the resulting level of anxiety. Conversely, the ECHC (European Conference on Health Communication) does not classify glyphosate as a carcinogen (European Chemicals Agency [ECHA], 2017). In November 2017, a study in the Journal of National Cancer Institute, following 54,000 agricultural workers over two decades, found that "glyphosate was not statistically significantly associated with cancer at any site" (The Washington Post, 2017).

In addition to the conversations on carcinogenic concerns, various studies have varied claims for correlations to celiac disease, autism, obesity, and other maladies and illnesses (Samsel \& Seneff, 2013). That said -- several comprehensive reviews by actual experts in human disease and biology have not found any epidemiological connection between any of these diseases and glyphosate (Mesnage \& Antoniou, 2017). Glyphosate is not an endocrine disruptor, it is not lipophilic, it is cleared mostly through the gut, and the rest through urine. Rats studied in various testing cleared all glyphosate from their system within a week, and in known human cases of acute glyphosate poisoning (drinking large amounts of glyphosate), the levels dropped to almost undetectable after 12 hours. The half-life has been estimated to be three hours, and in an analysis of 601 cases of self-poisoning attempts, the fatality rate was $3.2 \%$, fatalities associated with larger ingested amounts and greater age (American Chemical Council, 2021). This is in contrast to DDT which is an endocrine disruptor, lipophilic, (sticks to fatty substances), with a half-life of 6-10 years in humans (Tasman, 2017).

\section{Genetically Modified Crops}

Monsanto introduced the first widely used genetically modified crop (GMO - Genetically Modified Organism) in 1996 with the Roundup Ready® seed offerings (Hutchison \& Stuhl, 1996). This invention genetically modified the crop plants, which allowed the non-selective synthetic herbicides and specifically the glyphosate-containing Roundup to be used with selective utility in crops. Various health risks (organ damage, gastrointestinal and immune system disorders, accelerated aging, infertility, and cancer) have been studied and linked in various research to GMO crops. That said, there is still conflicting data and research reports that suggest confusion between GMO crops, the use of glyphosates, and the specific Roundup 


\section{Macrothink}

Case Studies in Business and Management

ISSN 2333-3324

2022, Vol. 9, No. 1

branded product that makes associations difficult. In addition to health risks, advocates against GMO crops are concerned with allergens and nutritional variances in these modifications, as well as the migratory/predatory nature of the GMO crops -- e.g., spreading, cross-pollinating, and otherwise affecting organic and heritage crops (Big Green Purse, 2020). Figure 5 suggests some of the confusion.

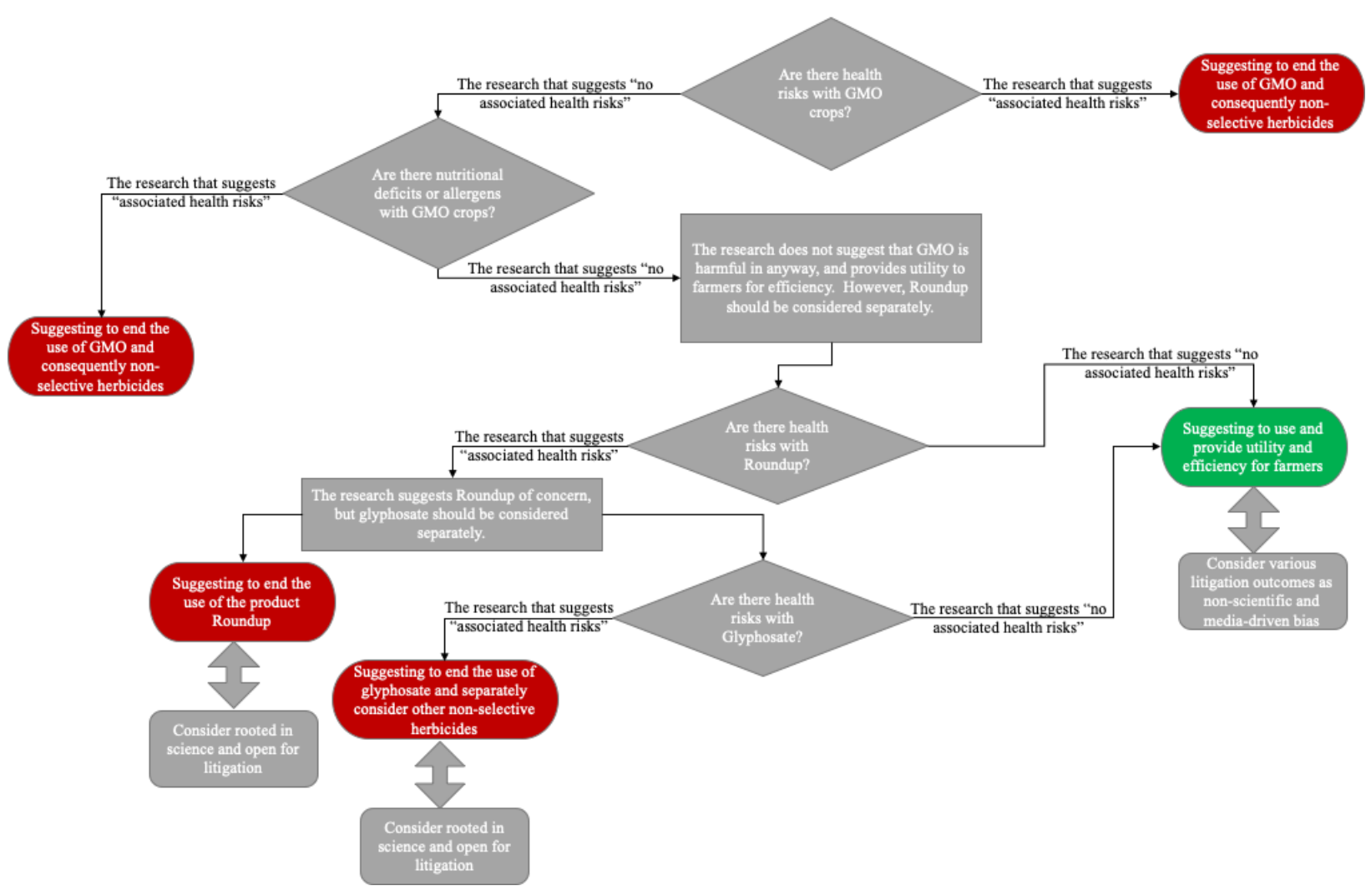

Figure 5. A Flow Chart of the Various Research Considerations

\section{The Regulation and Resistance (A few Countries in Example)}

\subsection{India}

The Government of India regulates the manufacture, sale, transport, export/import, etc. of pesticides under the guidelines of the Insecticides Act, 1968. The Insecticide Act, 1968 is administered through the Ministry of Agriculture, Department of Agriculture and Cooperation (DAC). Other vital issues of the pesticides industry such as preventing the use of spurious pesticides, employing quality standards and required testing, and review of pesticides used; are also looked after by the DAC to create awareness about judicious use of pesticides among the farming community. Central Insecticides Board and the Registration Committee are the agencies under the Department to regulate the manufacture, distribution, export, import, ban, and usage of pesticides. The Insecticide Act is enforced by the State Governments. The Department of Chemicals and Petrochemicals plays the role of a facilitator for the growth of 
the Industry. A few salient features of the act are as follows:

- No pesticide is allowed for production/import without registration. Compulsory registration is needed for the product at the central level and licenses for manufacture, formulation, and sale at the state level.

- Power to prohibit the import, manufacture, and sale of pesticides and also confiscate the stocks.

- Classifications of misbranded insecticides -- divided into the following categories viz; (a) misbranded, (b) substandard, (c) spurious, and (d) duplicate. These classifications have been fixed according to the severity of the offense.

- For an offense deemed to be misbranded, there is provision for issuing an administrative warning of the offense which may be compounded by imposing a fine up to INR 2,000. An offense deemed to be substandard shall be punishable for the first offense with fines up to INR 5,000 and for subsequent offenses with imprisonment for a term which may extend to 6 months or fines up to INR 10,000 or both.

- Similarly, an offense deemed to be adulterated shall be punishable with imprisonment for a term which may extend to 1 year or fine up to INR 20,000 or both for the first offense and for second and subsequent offenses with imprisonment for a term which may extend to 2 years or a fine up to INR 50,000 or both.

(Department of Agriculture - Government of Manipur, n.d.)

\subsection{The United States}

The Environmental Protection Agency (EPA) has maintained a similar position as the Bayer-Monsanto company in recent times and around recent/current data. They suggest that glyphosate is safe, and accordingly the federal government has been slow to engage in restrictions or other limitations. Some states or municipalities however have implemented restrictions and/or even bans. Private citizens have mobilized and worked to fight Bayer-Monsanto with accountability through litigation, campaigns, and the creation of alternative markets and co-ops that are herbicide, pesticide, and GMO-free (Zacune, March 2012). Many states have differing levels of restrictions, bans, or restraining orders - often for specific uses (example - not on railroad tracks, city properties, etc.). California has led other states in efforts to restrict, ban, and litigate - especially considering carcinogenic concerns (Carlson Law Firm, 2021).

\subsection{Europe}

Even though the European Union (e.g., the European Commission) has allowed continued use of glyphosates until December 15, 2022, and the ECHC (European Conference on Health Communication) does not classify glyphosate as a carcinogen (European Chemicals Agency [ECHA], 2017) - Austria banned use in July of 2019. Germany is phasing out the controversial weed killer by 2024 (European Commission, n.d.). 


\subsection{Globally}

Other countries around the world have some legislation and/or planned legislation pending regarding glyphosates including Malawi, Thailand, Vietnam, Sri Lanka, Oman, Kuwait, United Arab Emirates, Bahrain, Qatar, Saudi Arabia, St. Vincent, and the Grenadines, Bermuda, Austria, Belgium, Czech Republic, Denmark, France, Italy, and The Netherlands (Baum Hedlund Law, 2021).

\section{The Ethical Tension(s)}

Some entities (e.g., regulatory agencies, scientists, businesses, farmers, consumers, etc.) may grapple with what is known, what is not known, and where to draw the lines with various risk/opportunity conversations ethically. They could approach the use of glyphosate or Roundup from a Deontology ethical theory, where decisions are rooted in a sense of duty (The Ethics Centre, 2016b). In this theory - there may be a duty to engage toward preventing any harm or consequence (e.g., ban or discontinue use) or conversely a duty to stop disinformation and to facilitate feeding the masses and fight global hunger efficiently (e.g., continue and/or further use). Another consideration may be the theory of Consequentialism / Utilitarianism or the "ends justify the means" with the ethical actions aligned with the "most possible happiness and least possible pain" (The Ethics Centre, 2016a). In this case, the data might support ignoring outliers and focusing on significant beneficial outcomes. Another theory that could be employed is that of Ethical Absolutism as opposed to Relativism. Ethical absolutism theory argues for the existence of objective values and intrinsically moral acts, and that moral principles exist which are always valid and correct. In ethical relativism, the theory is that moral values are relative to some further instance (Jalsenjak, 2019). In these applications, an absolute (e.g., binary right/wrong, yes / no) or a relative (e.g., depending upon the situation) position might be considered. Ethical considerations of good versus harm and/or empirical right versus wrong may be applied differently by various stakeholder perspectives. Additionally, it is possible that simple business objectives and financial gain crowd out ethical considerations altogether. The reason this case study is interesting and an ethical dilemma is that the science has not empirically proved any one position enough to have legislation engage uniformly. Litigation follows some research, while the continuance of use follows others. The various informational discontinuities are seen in Figure 5, and each decision becomes subject to ethical consideration. 


\section{Part II --The Case Study Discussion}

\section{Instructions}

Each question may be assigned to individuals or groups. The assignee will consider the data in the case and/or outside research, and attempt to talk to the various components outlined in the question for consideration, and be prepared to present the findings, discussions, deliberations, tensions, and conclusions/recommendations.

\section{Question for Consideration}

\subsection{The Industrialization of Agriculture}

There are entire movements that are pushing for "buy local, farm-to-table, small farm, sustenance farming, etc." that are against some of the big business or industrialized farms. Consider the business case of efficiencies, scale, and the implications to consumers involving the variety, cost, and availability of food products - especially for impoverished nations or people. Using this case study as well as any outside research, consider the merits of large enterprises versus small farms.

1. Consider yields - do large agriculture companies with greater capital investments in equipment, science, and scale realize greater outcomes and yields, or do small farms with a more hands-on engagement extract the greater yields?

2. If smaller farms do have the potential for greater yields per acre, is this scalable to feed the world in a better way or not?

3. Consider the cost of the end product - can the small farms compete with the larger enterprises' economies of scale, and does this affect less affluent populations in terms of hunger and poverty?

\subsection{The Globalization of Agriculture}

Some movements are reacting to the urgency of climate change and suggesting that globalization of food is a contributor. If a United States consumer's rice is from China, wine is from France, spices from India, cheese is from Italy, fish is from Thailand, and apples are from New Zealand - there is a resulting carbon footprint from the logistics of this globalization. As cultural tastes and trends have hybridized through globalization, the demand for specialization, variety, and ethnically diverse offerings have increased. Additionally, some geographies, climates, and technologies allow for production efficiencies of certain food products - suggestive of the benefits of globalization and trade. Consider the pros and cons of local or domestic farming in contrast to the globalization of agribusiness. Firms globalize for two reasons - either A) market (new markets/products or expansion potential of the current market/products), or B) production (cost efficiencies/savings in some or several factors of production - e.g., labor, material, logistics, capital, etc.). 


\section{Macrothink}

1. Consider the large multi-national enterprises that have expanded agribusiness into multiple countries - in what ways is this beneficial and in what ways is this detrimental? Overall - should these exist? Why?

2. Consider globalization through exports - moving variety and supply around the world. In what ways is this beneficial and in what ways is this detrimental? Overall - should this practice exist? On the current scale or magnitude? Why?

\subsection{The Transparency Issue for Consumers}

Entire new markets and agendas are promoting the "No GMO" (Genetically Modified Organism), "Organic," etc. - and then there is also significant literature and science supporting both safety and risks / collateral issues for synthetic herbicides - especially glyphosates and even more particularly, Roundup. As conscientious consumers attempt to act responsibly, consider the transparency and confusion that exists around science, propaganda, and economics.

1. After reviewing this case - from a position as consumers: A) Were you surprised that there are strong arguments on both sides? B) Were you confused as science seems to support multiple positions?

a. What recommendations should be considered for improved understanding and/or transparency?

b. What might be some of the "business" reasons for these tensions (for instance - big business/money made on herbicides vs big business/money made on counter-markets such as non-GMO).

c. Do these tensions harm consumers or provide market economics (e.g., competition / favorable market climates)?

d. Does the globalization aspect increase confusion or increase attention and transparency (differing regulatory responses around the world)? How?

\subsection{The Force-Field Analysis of Roundup}

Using this example force field analysis template, add your own driving forces and restraining forces, and your own rankings (replacing all numerical values and sums from the example) to help justify your position in this ethical dilemma. Note: The example shows equilibrium, but your team or consideration may show significant forces toward one outcome or the other based on your weighting of the facts and research. 


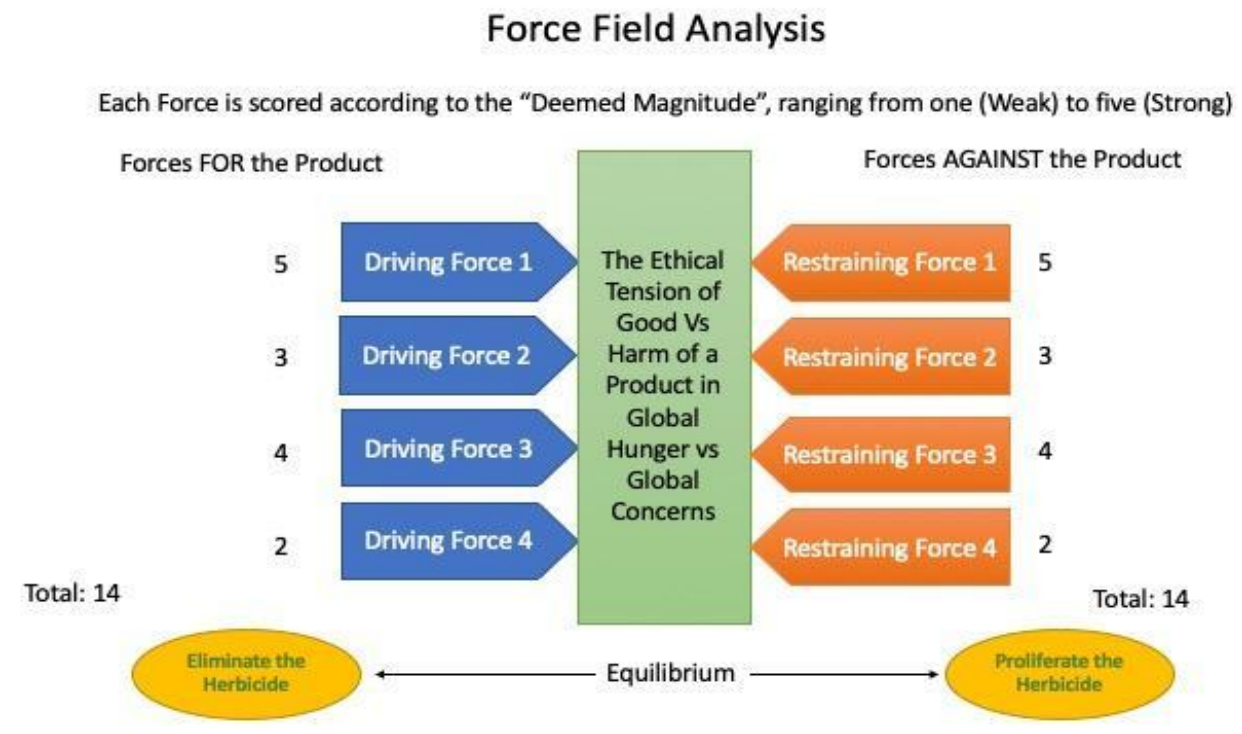

\subsection{Ethical Models and Theories in Play}

Consider the various ethical theories/models introduced in this case.

1. What ethical theory supports the glyphosate manufacturers' positions?

2. What ethical theory supports the regulatory agencies' positions?

3. Do they differ and why?

\subsection{The GMO Associative Collateral}

Realizing that creating a selective utility for a non-selective herbicide resulted in genetic engineering modifications of various crops - a large portion of agricultural food products are genetically modified. The responding non-GMO movements and markets are growing through significant literature and propaganda with scientific references.

1. Consider if the non-GMO is really about the GMO crop vs heritage breeds, or if it is a way to avoid the glyphosate concerns.

2. Consider other reasons crops may be genetically modified, and benefits that could fall collateral to the glyphosate or specifically the Roundup reactions.

a) What benefit or harm could the avoidance of GMO foods/crops cause?

b) What suggestions should be considered?

\subsection{Whose Job Is It?}

Considering the various data and science, various regulatory agencies and/or governments respond differently - up to and/or including phase-out programs. Farmers have often been faced with various and conflicting data and science, and then had to choose between conventional tillage and cultivation, or chemically-aided methodologies. Montesano and other large businesses not only sold herbicides but also sold seeds. These larger businesses 
were instrumental in the development and promotion of genetic modifications to facilitate non-selective herbicide use in selective applications. Consider the roles and responsibilities of all parties:

1. Is it the job of governments to regulate responsibility and risk/opportunity considerations with scientific backing?

a. Is this governmental overreach to legislate moral and ethical decision-making?

i. Because of conflicts of interest in big business

ii. Because of failures of big business

iii. Because of the inconclusiveness of the science and the concern of the citizens

iv. Because of globalization and therefore the lack of reach of one universal regulating body?

2. Is it the job of big business (e.g., Corporate Social Responsibility or CSR) to:

a. Avoid all risks and play it safe where human consumption/safety is involved?

b. Defer to Science to support conclusive risk (STOP) vs inconclusive risk (GO) compared to conclusive benefits (GO) vs inconclusive benefits (EVALUATE)?

c. Consider the stewardship role of the company's economic position and shareholder values, and act in the best interest of the company's profits and viability?

d. Avoid conflicts of interest and monopolies (e.g., herbicide and seed engineering, production, and sales) OR find complementary markets and avenues of growth - capitalize on opportunities and provide a "full service" portfolio to their customer base?

3. Is it the job of the farmer to:

a. Get quality produce with the highest yields OR certify the health and safety of their produce?

b. Understand all the science and dilemmas associated with what products are sold at the local seed store or understand how to safely follow the scientific instructions of the "experts" at the seed store?

4. Is it the job of the consumer to buy produce that -

a. Looks fresh and is sold by a reputable store 
b. Is supported by a significant amount of scientific research that they may not understand

c. Is supported by their government and/or a regulatory agency

5. And Finally -

a. Where (or with whom) does responsibility lie from 1 - 4 above?

b. What are the lessons from this agribusiness example that extend to other businesses or industries?

\section{References}

American Chemical Council. (2021). Glyphosate and autism: Back to a fake news story (English Translation). Campaign for Accuracy in Public Health Research. Retrieved October 31, 2021, from

https://campaignforaccuracyinpublichealthresearch.com/glyphosate-and-autism-back-to-a-fak e-news-story-english-translation/

Baer, K., \& Marcel, B. (2014). Glyphosate. In Encyclopedia of toxicology (pp. 767-769). Elsevier. https://doi.org/10.1016/b978-0-12-386454-3.00148-2

Baum Hedlund Law. (2021, August). Where is glyphosate banned? Monsanto Roundup Lawsuit. Retrieved October 31, 2021, from

https://www.baumhedlundlaw.com/toxic-tort-law/monsanto-roundup-lawsuit/where-is-glypho sate-banned-/

Bayer. (n.d.-a). Benefits and safety of glyphosate. Cropscience.bayer.com.

https://www.cropscience.bayer.com/sites/cropscience/files/inline-files/Glyphosate\%20Benefit s\%20and\%20Safety\%20booklet.pdf

Bayer. (n.d.-b). Shaping agriculture. Cropscience.Bayer.com.

https://www.cropscience.bayer.com/innovations/crop-protection/herbicides

Bellon, T. (2018, August 10). Monsanto ordered to pay \$289 million in world's first Roundup cancer trial. Reuters.

https://www.reuters.com/article/us-monsanto-cancer-lawsuit-idUSKBN1KV2HB

Benbrook, C. M. (2016). Trends in glyphosate herbicide use in the United States and globally. Environmental Sciences Europe, 28(1). https://doi.org/10.1186/s12302-016-0070-0

Benbrook, C. M. (2019). How did the US EPA and IARC reach diametrically opposed conclusions on the genotoxicity of glyphosate-based herbicides? Environmental Sciences Europe, 31(1). https://doi.org/10.1186/s12302-018-0184-7

Big Green Purse. (2020). The 7 most important reasons to avoid GMOs. http://biggreenpurse.com/the-7-most-important-reasons-to-avoid-gmos/

Brown, K., Stephenson, D. O., Gueltig, B., \& Willis, J. (2019, November 1). 10 things you should know about glyphosate. LSU AgCenter Articles. 
https://www.lsuagcenter.com/profiles/aiverson/articles/page1573150527569

Bus, J. S. (2015). Analysis of moms across America report suggesting bioaccumulation of glyphosate in US. mother's breast milk: Implausibility based on inconsistency with available body of glyphosate animal toxicokinetic, human biomonitoring, and physico-chemical data. Regulatory Toxicology and Pharmacology, 73(3), 758-764.

https://doi.org/10.1016/j.yrtph.2015.10.022

Carlson Law Firm. (2021, February 10). Which Countries and U.S. States are Banning Roundup? The Carlson Law Firm. Retrieved October 31, 2021, from

https://www.carlsonattorneys.com/news-and-update/banning-roundup

Clark, D. (n.d.). How to be healthy naturally - Views of a research scientist | Glyphosate toxicity summary data. HerbScientist.com.

https://herbscientist.com/glyphosate-toxicity-summary-data/

Cressey, D. (2015). Widely used herbicide linked to cancer. Nature.

https://doi.org/10.1038/nature.2015.17181

Cuhra, M. (2015). Review of GMO safety assessment studies: Glyphosate residues in Roundup Ready crops is an ignored issue. Environmental Sciences Europe, 27(1).

https://doi.org/10.1186/s12302-015-0052-7

Department of Agriculture - Government of Manipur. (n.d.). The Insecticides Act, 1968. Agrimanipur. http://www.agrimanipur.gov.in/the-insecticides-act-1968/

Directorate of Plant Protection, Quarantine, and Storage. (2021). [various descriptions of glyphosate use]. http://ppqs.gov.in/. http://ppqs.gov.in/

Dukeshire, S. (2013). Concentration, consolidation, and control: How big business dominates the food system [Book Review of "Foodopoly"]. Journal of Agriculture, Food Systems, and Community Development, 4(1), 171-173. https://doi.org/10.5304/jafscd.2013.041.010

Environmental Protection Agency. (September 12, 2016). Glyphosate issue paper: Evaluation of carcinogenic potential [Issue Paper]. EPA - EPA's Office of Pesticide Programs.

https://www.epa.gov/sites/default/files/2016-09/documents/glyphosate_issue_paper_evaluatio n_of_carcincogenic_potential.pdf

European Chemicals Agency. (2017). Glyphosate not classified as a carcinogen by ECHA (ECHA/PR/17/06). ECHA (An Agency of the European Union).

https://echa.europa.eu/-/glyphosate-not-classified-as-a-carcinogen-by-echa

European Commission. (n.d.). Status of glyphosate in the EU.

https://ec.europa.eu/food/plants/pesticides/approval-active-substances/renewal-approval/glyp hosate_en

Federation of Indian Chambers of Commerce \& Industry. (2015). Knowledge paper on safer and judicious use of crop protection chemicals and applications of green chemistries (Industry Reports, Analysis by Tata Strategic) [Report]. FICCI. 
https://ficci.in/spdocument/20541/Kowledge-Paper-chem.pdf

Friedmann, H. (1991). Changes in the international division of labor: Agri-food complexes and export agriculture. In W. H. Friedland, L. Busch, F. H. Buttel, \& A. P. Rudy (Eds.), Towards a new political economy of agriculture (1st ed.). Routledge. https://doi.org/10.4324/9780429269493

Global Agriculture. (n.d.). Global Agriculture. https://www.globalagriculture.org/

Gonzales, R. (2019, May 13). California jury awards \$2 Billion to couple in Roundup weed killer cancer trial. Capradio (NPR). Retrieved November 7, 2021, from https://www.capradio.org/news/npr/story/?storyid=723056453

Google Dictionary. (n.d.). Pesticide. Retrieved October 30, 2021, from https://www.google.com/search?q=pesticides+definition\&oq=pesticides\&aqs=chrome.1.69i5 7j0i131i433i512j0i51217j0i457i512.4161j0j15\&sourceid=chrome\&ie=UTF-8

Gronau, I. (2017, September 16). No-tilling tames slopes, makes tough soils productive. No-Till Farmer: Crop Protection, Soil Health, Water Management.

https://www.no-tillfarmer.com/articles/7029-no-tilling-tames-slopes-makes-tough-soils-produ ctive? $\mathrm{v}=$ preview

Guyton, K. Z., Loomis, D., Grosse, Y., El Ghissassi, F., Benbrahim-Tallaa, L., Guha, N., Scoccianti, C., Mattock, H., \& Straif, K. (2015). Carcinogenicity of tetrachlorvinphos, parathion, malathion, diazinon, and glyphosate. The Lancet Oncology, 16(5), 490-491. https://doi.org/10.1016/s1470-2045(15)70134-8

Henderson, A. M., Gervais, J. A., Luukinen, B., Buhl, K., Stone, D., Cross, A., \& Jenkins, J. (2010). Glyphosate general fact sheet [Data set]. National Pesticide Information Center, Oregon State University Extension Services. http://npic.orst.edu/factsheets/glyphogen.html

Hoss, N. E., Al-Khatib, K., Peterson, D. E., \& Loughin, T. M. (2003). Efficacy of glyphosate, glufosinate, and imazethapyr on selected weed species. Weed Science, 5(1), 110-117. https://www.jstor.org/stable/4046633

Hutchison, A., \& Stuhl, A. (1996, September 4). "Roundup Ready": The first widely used genetically modified crop. Environment \& Society Portal.

https://www.environmentandsociety.org/tools/keywords/roundup-ready-first-widely-used-gen etically-modified-crop

International Agency for Research on Cancer | World Health Organization (WHO). (2017). Some organophosphate insecticides and herbicides (Volume 112 - IARC Monographs on the Evaluation of Carcinogenic Risks to Humans) [Report]. IARC Monographs. https://monographs.iarc.who.int/wp-content/uploads/2018/07/mono112.pdf

International Agency for Research on Cancer. (2021). Agents Classified by the IARC Monographs, Volumes 1-129. Monographs IARC World Health Organization. Retrieved October 31, 2021, from https://monographs.iarc.who.int/agents-classified-by-the-iarc/ 
Jalsenjak, B. (2019). Ethical absolutism v ethical relativism. In S. Idowu, R. Schmidpeter, N. Capaldi, L. Zu, M. Del Baldo, \& R. Abreu (Eds.), Encyclopedia of sustainable management. Springer International Publishing. https://doi.org/10.1007/978-3-030-02006-4_116-1

Katz, E., \& Stark, O. (1986). Labor migration and risk aversion in less developed countries. Journal of Labor Economics, 4(1), 134-149. https://doi.org/10.1086/298097

Lotz, L. P., Christensen, S., Cloutier, D., Quintanilla, C., Legere, A., Lemieux, C., Lutman, P. W., Iglesias, A., Salonen, J., Sattin, M., Stigliani, L., \& Tei, F. (1996). Prediction of the competitive effects of weeds on crop yields based on the relative leaf area of weeds. Weed Research, 36(1), 93-101. https://doi.org/10.1111/j.1365-3180.1996.tb01805.x

Mesnage, R., \& Antoniou, M. N. (2017). Facts and fallacies in the debate on glyphosate toxicity. Frontiers in Public Health, 5. https://doi.org/10.3389/fpubh.2017.00316

Mesnage, R., Defarge, N., Spiroux de Vendômois, J., \& Séralini, G.-E. (2014). Major pesticides are more toxic to human cells than their declared active principles. BioMed Research International, 2014, 1-8. https://doi.org/10.1155/2014/179691

Myers, J., Antoniou, M. N., Blumberg, B., Carroll, L., Colborn, T., Everett, L. G., Hansen, M., Landrigan, P. J., Lanphear, B. P., Mesnage, R., Vandenberg, L. N., Vom Saal, F. S., Welshons, W. V., \& Benbrook, C. M. (2016). Concerns over use of glyphosate-based herbicides and risks associated with exposures: A consensus statement. Environmental Health, 15(1). https://doi.org/10.1186/s12940-016-0117-0

Norberg-Hodge, H., Merrifield, T., \& Gorelick, S. (2002). Bringing the food economy home: Local alternatives to global agribusiness. Zed Books.

Portier, C. J., Armstrong, B. K., Baguley, B. C., Baur, X., Belyaev, I., Bellé, R., Belpoggi, F., Biggeri, A., Bosland, M. C., Bruzzi, P., Budnik, L., Bugge, M. D., Burns, K., Calaf, G. M., Carpenter, D. O., Carpenter, H. M., López-Carrillo, L., Clapp, R., Cocco, P.,...Zhou, S.-F. (2016). Differences in the carcinogenic evaluation of glyphosate between the International Agency for Research on Cancer (IARC) and the European Food Safety Authority (EFSA). Journal of Epidemiology and Community Health, 70(8), 741-745.

https://doi.org/10.1136/jech-2015-207005

PR Newswire. (July 31, 2018). Research report on China's glyphosate industry (2018-2022). Cision PR Newswire.

https://www.prnewswire.com/news-releases/research-report-on-chinas-glyphosate-industry-2 018-2022-300689149.html

Reuters. (2021, August 10). Bayer loses third appeals case over glyphosate weedkiller. Reuters.

https://www.reuters.com/business/healthcare-pharmaceuticals/bayer-loses-third-appeals-caseover-glyphosate-weedkiller-2021-08-10/

Rew, L. J., Lehnhoff, E. A., \& Maxwell, B. D. (2007). Non-indigenous species management using a population prioritization framework. Canadian Journal of Plant Science, 87(5), 
1029-1036. https://doi.org/10.4141/cjps07121

Robinson, G. M. (2018). Globalization of agriculture. Annual Review of Resource Economics, 10(1), 133-160. https://doi.org/10.1146/annurev-resource-100517-023303

Robinson, G. M., \& Carson, D. A. (2015). Handbook on the globalisation of agriculture. Edward Elgar Publishing.

Roundup. (n.d.). Where there's a weed there's a way. https://www.roundup.com/en-us

Samsel, A., \& Seneff, S. (2013). Glyphosate, pathways to modern diseases II: Celiac sprue and gluten intolerance. Interdisciplinary Toxicology, 6(4), 159-184.

https://doi.org/10.2478/intox-2013-0026

Sigrimis, N., Antsaklis, P., \& Groumpos, P. P. (2001). Advances in control of agriculture and the environment. IEEE Control Systems, 21(5), 8-12. https://doi.org/10.1109/37.954516

Skurski, T. C., Maxwell, B. D., \& Rew, L. J. (2013). Ecological tradeoffs in non-native plant management. Biological Conservation, 159, 292-302.

https://doi.org/10.1016/j.biocon.2012.10.017

Sokolove Law. (n.d.). Roundup ${ }^{\circledR}$ Lawsuit. Retrieved October 31, 2021, from https://www.sokolovelaw.com/product-liability/monsanto-roundup/

Stark, O. (1984). Rural-to-urban migration in IDCS: A relative deprivation approach. Economic Development and Cultural Change, 32(3), 475-486.

https://doi.org/10.1086/451401

Statista. (2016). Glyphosate use worldwide from 1994 to 2014 (in 1,000 kilograms) [Data set]. https://www.statista.com/statistics/567250/glyphosate-use-worldwide/

Sung, J. (2018). The fourth industrial revolution and precision agriculture. In Automation in agriculture - securing food supplies for future generations. InTech. https://doi.org/10.5772/intechopen.71582

Székács, A., \& Darvas, B. (2011). Forty years with glyphosate. In M. N. Hasaneen (Ed.), Herbicides: Properties, Synthesis, and Control of Weeds (pp. 247-284). InTech.

Tarazona, J. V., Court-Marques, D., Tiramani, M., Reich, H., Pfeil, R., Istace, F., \& Crivellente, F. (2017). Glyphosate toxicity and carcinogenicity: A review of the scientific basis of the European Union assessment and its differences with IARC. Archives of Toxicology, 91(8), 2723-2743. https://doi.org/10.1007/s00204-017-1962-5

Tasman, J. (March 13, 2017). GMO building blocks: 5 of 17 - could glyphosate be another case like DDT or Thalidomide? WordPress (GMO Building Blocks). http://fafdl.org/gmobb/5-of-17-could-glyphosate-be-another-case-like-ddt-or-thalidomide/

The Ethics Centre. (2016a, February 15). Ethics Explainer: Consequentialism. https://ethics.org.au/ethics-explainer-consequentialism/

The Ethics Centre. (2016b, February 18). Ethics Explainer: Deontology. 
https://ethics.org.au/ethics-explainer-deontology/

The Washington Post. (2017, November 10). UPDATE 2-Large U.S. farm study finds no cancer link to Monsanto weedkiller. The Washington Post. Retrieved October 31, 2021, from https://www.washingtonpost.com/national/health-science/study-finds-no-firm-link-between-c hemical-in-popular-weedkiller-and-cancer/2017/11/10/1f8096c0-c578-11e7-aae0-cb18a8c29c 65_story.html

Travlos, I., Cheimona, N., \& Bilalis, D. (2017). Glyphosate efficacy of different salt formulations and adjuvant additives on various weeds. Agronomy, 7(3), 60.

https://doi.org/10.3390/agronomy7030060

United Nations Educational, Scientific, and Cultural Organization. (2017). Culture for sustainable development. Unesco.org. Retrieved May 30, 2021, from

http://www.unesco.org/new/en/culture/themes/culture-and-development/the-future-we-want-t he-role-of-culture/globalization-and-culture/\#: :text=While $\% 20$ this $\% 20$ phenomenon $\% 20$ pro motes $\% 20$ the,identity $\% 2 \mathrm{C} \% 20$ exclusion $\% 20$ and $\% 20$ even $\% 20$ conflict.

United States Environmental Protection Agency. (n.d.). CADDIS Volume 2 | Herbicides. EPA.gov/Caddis Volume 2.

https://www.epa.gov/caddis-vol2/caddis-volume-2-sources-stressors-responses-herbicides

Uri, N. D. (2000). Perceptions on the use of no-till farming in production agriculture in the United States: An analysis of survey results. Agriculture, Ecosystems \& Environment, 77(3), 263-266. https://doi.org/10.1016/s0167-8809(99)00085-7

US Environmental Protection Agency. (n.d.). Glyphosate. Ingredients used in pesticide products. https://www.epa.gov/ingredients-used-pesticide-products/glyphosate

Washington State University. (2015, July 23). U.S. breast milk is glyphosate free: Study is first independently verified look for the presence of Roundup ingredient in human milk. Science Daily. https://www.sciencedaily.com/releases/2015/07/150723133120.htm

Wechsler, S. J., Smith, D., McFadden, J., Dodson, L., \& Williamson, S. (2019, October 1). The use of genetically engineered dicamba-tolerant soybean seeds has increased quickly, benefiting adopters but damaging crops in some fields. U.S. Department of Agriculture (USDA) economic research service: Crop and livestock practices.

https://www.ers.usda.gov/amber-waves/2019/october/the-use-of-genetically-engineered-dica mba-tolerant-soybean-seeds-has-increased-quickly-benefiting-adopters-but-damaging-crops-i n-some-fields/

Yenduri, A., \& Sumant, O. (2019). Herbicides Market [Data set]. Allied Market Research. https://www.alliedmarketresearch.com/herbicides-market

Zacune, J. (March 2012). Combatting Monsanto grassroots resistance to the corporate power of agribusiness in the era of the 'green economy' and a changing climate ( $\mathrm{R}$. Hall, Ed.). La Via Campesina.

https://viacampesina.org/en/wp-content/uploads/sites/2/2012/04/Monsanto-Publication-EN-Fi 
$\underline{\text { nal-Version.pdf }}$

Zhang, L., Rana, I., Shaffer, R. M., Taioli, E., \& Sheppard, L. (2019). Exposure to glyphosate-based herbicides and risk for non-Hodgkin lymphoma: A meta-analysis and supporting evidence. Mutation Research/Reviews in Mutation Research, 781, 186-206. https://doi.org/10.1016/j.mrrev.2019.02.001

Zhao, X., Liu, S.-L., Pu, C., Zhang, X.-Q., Xue, J.-F., Ren, Y.-X., Zhao, X.-L., Chen, F., Lal, R., \& Zhang, H.-L. (2017). Crop yields under no-till farming in China: A meta-analysis. European Journal of Agronomy, 84, 67-75. https://doi.org/10.1016/j.eja.2016.11.009

\section{Disclosures \& Acknowledgements}

Disclosures: None of the authors are affiliated with any company that manufactures or distributes herbicides, and declare no known conflicts of interest.

Acknowledgments: In addition to the authors, various faculty contributed research, and are acknowledged: Dr. S. Usha Nandhini; Dr. V. Kavitha; Dr. B. Navaneetham; Dr. R. Minithra; and Dr. T. Pheifer.

\section{Copyrights}

Copyright for this article is retained by the author(s), with first publication rights granted to the journal.

This is an open-access article distributed under the terms and conditions of the Creative Commons Attribution license (http://creativecommons.org/licenses/by/4.0/). 